\title{
MEDICALIZAÇÃO DA EDUCAÇÃO E OS SENTIDOS DO NÃO APRENDER
}

\author{
MEDICALIZACIÓN DE LA EDUCACIÓN Y LOS SENTIDOS \\ DE NO APRENDER
}

\section{MEDICALIZATION OF EDUCATION AND THE SENSES OF NOT LEARNING}

\author{
Claudia Regina Mosca GIROTO ${ }^{1}$ \\ Ana Paula BERBERIAN ${ }^{2}$ \\ Ana Paula de Oliveira SANTANA ${ }^{3}$ \\ Organizadoras
}

Profissionais das áreas da Saúde e da Educação, críticos de abordagens medicalizantes, são unânimes em afirmar que tais abordagens descaracterizam e escamoteiam a condição humana, uma vez que decorrem de uma lógica reducionista/determinista focada no indivíduo e, em especial, em sua dimensão orgânica. Se podemos acompanhar um certo consenso, entre tais profissionais, de que essa lógica está comprometida, nacional e internacionalmente, com a gênese de um projeto de "sociedade moderna", edificada sob princípios da produtividade, competitividade e consumo, interessa destacar como, a partir de meados da década de 1980, denúncias acerca de seu caráter segregacionista e discriminatório ganham espaços e passam a circular em vários contextos e instituições.

Evidenciando tal fato, ganha força, nas últimas décadas, em nosso país, um processo crescente na organização de grupos envolvendo profissionais de diferentes áreas comprometidos com movimentos, ações, produção de conhecimentos capazes de fazer frente e resistir às ações que objetivem a medicalização da vida em todas as suas dimensões e

${ }^{1}$ Universidade Estadual Paulista (UNESP), Marília - SP - Brasil. Docente no Programa de Pós-Graduação em Educação (PPGE) e do Departamento de Educação Especial, Faculdade de Filosofia e Ciências (FFC). Docente no Programa de Pós-Graduação em Educação Escolar (PPGEE), Faculdade de Ciências e Letras (FCLAr/UNESP) - Araraquara. Doutora em Educação (UNESP). Projeto CNPq Processo no 406241/2016-3. ORCID: https://orcid.org/0000-0001-6267-8085. E-mail: claudia.mosca@unesp.br

${ }^{2}$ Universidade Tuiuti do Paraná (UTP), Curitiba - PR - Brasil. Professora no curso de Graduação em Fonoaudiologia e no Programa de Pós-Graduação em Distúrbios da Comunicação. Doutorado em História (PUC/SP). Apoio Financeiro CNPQ/Produtividade em Pesquisa. Processo $\mathrm{n}^{\circ}$ 306523/2017-5. ORCID: https://orcid.org/0000-0001-7176-7610. E-mail: ana.berberian@utp.br

${ }^{3}$ Universidade Federal de Santa Catarina - (UFSC), Florianópolis - SC - Brasil. Professora Associada no Curso de Fonoaudiologia e da Pós-graduação em Linguística. Doutorado em Linguística (UNICAMP). ORCID: https://orcid.org/0000-0002-9508-9866. E-mail: anaposantana@hotmail.com 
esferas, em especial no contexto da Educação, e que estão a serviço da naturalização das desigualdades e injustiças sociais, transformando-as em doenças e/ou distúrbios.

Efeitos nocivos, que enredam professores, alunos e familiares, produzidos a partir de uma rede discursiva medicalizante que circula no contexto escolar, seja materializada em falas desqualificatórias, seja em classificações, avaliações veiculadas em laudos e relatórios, têm sido confrontados a partir de visões contra-hegemônicas comprometidas com o desnudamento de suas contradições e de seus efeitos negativos.

Ao longo de nossa história podemos acompanhar, por um lado, a difusão de uma lógica causal entre condições restritas de aprendizagem e deficiências inerentes aos alunos e às suas famílias (de natureza moral, comportamental, psíquica e orgânica) e a perpetuação da máxima de que educadores, familiares e alunos devem aderir, sem questionamentos, a diagnósticos e tratamentos determinados por especialistas da saúde e, por outro lado, observar que tais verdades vêm sendo apontadas como discriminatórias, uma vez que destituem os sujeitos de um lugar e os colocam numa posição de vulnerabilidade.

Consideramos que a possibilidade de ressignificação e superação de posições medicalizantes emerge de movimentos comprometidos com a crítica, imperativa, acerca de posições que individualizam e naturalizam os processos de ensino-aprendizagem, bem como, da explicitação dos determinantes econômicos, políticos e culturais que ao (re) produzir (em) desigualdades e injustiças sociais restringem a democratização dos bens materiais e simbólicos produzidos pela humanidade.

A temática da "Medicalização da Educação e os sentidos do não aprender" aqui apresentada foi motivada pelo reconhecimento da necessidade de fazer circular/ecoar estudos que ofereçam elementos para o entendimento dos processos medicalizantes como restritivos para o acesso ao conhecimento escolar-acadêmico e, portanto, para a consolidação do direito à Educação.

Nessa direção, os artigos que integram o presente Dossiê partem do pressuposto de que para o enfrentamento de tais processos são necessários a sistematização e o implemento de abordagens teóricas e práticas que contribuam para a promoção da consciência humana. Nesses artigos é explicitado o compromisso com a verticalização de análises que deflagram reflexões sobre como visões e procedimentos medicalizantes, que incidem sob processos educacionais envolvidos desde a Educação Básica até o Ensino Superior, instituem, paradoxalmente, experiências do não aprender.

Apresentado pela Revista Ibero-Americana de Estudos em Educação (RIAEE), este dossiê contempla 16 artigos de autoria de pesquisadores vinculados a diferentes instituições 
de ensino superior: Universidade Federal de Alagoas (UFAL); Centro de Educação da Universidade Federal de Alagoas (CEDU/UFAL), Universidade Federal de Pelotas (UFPel), Pontifícia Universidade Católica de São Paulo (PUC-SP), Universidade Federal do Ceará (UFC), Universidade Federal de Uberlândia (UFU), Universidade Estadual Paulista (UNESP/SP), Universidade do Estado do Rio de Janeiro (UERJ), Universidade Federal do Paraná (UFPR), Universidade Estadual do Paraná (UNESPAR), Faculdade Evangélica Mackenzie do Paraná (FEMPAR), Universidade Tuiuti do Paraná (UTP), Universidade Federal de Santa Catarina (UFSC), Universidade Nove de Julho (UNINOVE), Universidade Federal da Paraíba (UFPB), Centro Universitário de João Pessoa (UNIPÊ), Universidade Estadual do Centro-Oeste do Paraná (UNICENTRO), Universidade Federal da Bahia (UFBA) e Universidade Federal do Rio Grande do Sul (UFRGS).

Delimitados a partir de diferentes recortes temáticos e metodológicos, esses artigos convergem quanto à necessidade do enfrentamento e da superação, no campo da Educação, de uma mesma problemática social, ou seja, a que (re) produz e naturaliza conhecimentos e práticas normatizadoras, excludentes e discriminatórias como estruturantes do sistema, das instituições e das inter-relações educacionais. A leitura desses artigos nos convoca a uma escuta crítica e responsiva de relatos de estudantes, de profissionais da saúde e da educação, fazendo ecoar experiências de sofrimento e de segregação vividas por aqueles que, por não atenderem às demandas educacionais, são considerados portadores de dificuldades, deficiências, patologias individuais e, como tal, devem ser classificados/diagnosticados e tratados.

Nesses artigos, discursos veiculados em manuais, laudos, relatórios, bem como, em enunciados produzidos por estudantes e por profissionais da saúde e da educação são tratados como processos de subjetivação constituídos por forças contraditórias e, por vezes antagônicas, que levam à aderência ou à recusa de um modo de ser/pensar medicalizante.

Com o compromisso de abordar criticamente dispositivos de poder que constituem e naturalizam a noção de distúrbios/deficiências e, por extensão, alicerçam os sentidos do "não aprender", os artigos em questão rejeitam abordagens que reduzem o aluno à condição de objeto do aprender, dando visibilidade ao que é apagado, escuta ao que é silenciado acerca das restritas condições materiais e subjetivas que destituem parcela significativa da população brasileira do direito a uma Educação de qualidade.

Os artigos foram organizados considerando, inicialmente, estudos cujos autores se debruçaram sobre aspectos amplos que contribuem para a sistematização e para o implemento de princípios, critérios e práticas, produzidas nos contextos da saúde e educação, que 
subsidiam práticas pedagógicas medicalizantes, seguidos dos artigos que versam sobre ações intersetoriais que abordam, sem suas discussões, a (re)produção de práticas clínicaspedagógicas que produzem a medicalização e condições para o não aprender versus a resistência a tais práticas em contextos educacionais e clínicos.

$\mathrm{O}$ artigo "Infância e medicalização da vida: uma análise sobre a produção diagnóstica e seus nexos com os processos de escolarização" enfatiza a crescente ampliação de diagnósticos de transtornos e deficiências, particularmente no que diz respeito ao público infantil, o que refrata na sua proliferação nos contextos educacionais resultante do que é denominado, nesse artigo, como inflação diagnóstica e seus efeitos, que tendem a supervalorizar processos de medicalização da vida e da infância, no que tange especialmente aos processos de escolarização.

Dessa perspectiva, é apresentado um breve histórico a respeito da constituição do Diagnostic and Statistical Manual for Mental Disease (DSM), da primeira à quinta edição, publicado pela Associação Psiquiátrica Americana (APA), situando-o, no contexto contemporâneo, a partir dos impactos desse manual nessa produção diagnóstica que, invariavelmente, acarreta a redução dos fenômenos humanos a manifestações comportamentais que intensificam a culpabilização do sujeito frente às demandas dos processos de escolarização, principalmente nas situações que não corresponde aos padrões idealizados de normalidade. Também são destacadas as recentes críticas ao DSM tecidas pela própria comunidade psiquiátrica e, especialmente, por um de seus mais proeminentes membros: Allen Frances, coordenador do grupo responsável pela elaboração da versão de 1994 desse manual.

A discussão circunstancia a relação entre a quinta versão do DSM-5 e as ações, definidas em legislação que orientam políticas públicas educacionais e de saúde que, por sua vez, orientam a identificação precoce e a definição de critérios preditivos para os transtornos do espectro do autismo (TEA), bem como, a atuação de profissionais vinculados à rede do Sistema Único de Saúde (SUS) quanto à saúde das pessoas com deficiência e de suas famílias, o que intensifica, conforme explicitado no texto, "a lógica da prevenção", bem como, a "antecipação de riscos" para as patologias de natureza psiquiátricas. Tanto essa lógica quanto essa antecipação valorizam, sobremaneira, aspectos comportamentais e as explicações etiológicas de natureza biológica para o fracasso escolar, o que tende a silenciar as singularidades características dos processos de constituição do ser criança e ser aluno.

No artigo "Novas abordagens em psiquiatria no século XXI: a escola como locus de prevenção e promoção em saúde mental” é demonstrada de que forma a escola vem se 
constituindo historicamente como locus de pesquisas sobre psiquiatria, particularmente a psiquiatria do desenvolvimento, suas estratégias de disseminação e legitimação do controle social e educacional, incidindo sobre seleção de crianças suspeitas e de risco, tomando o universo escolar de forma individualizada para o processo de medicalização da infância.

A partir de pesquisa bibliográfica e documental, é destacado o processo de compreensão da escola como local para a intervenção preventiva em saúde mental voltada a crianças e adolescentes, comumentemente por meio da instrumentalização dos educadores, com vista à identificação e/ou encaminhamentos de alunos considerados suspeitos ou de risco para tais problemas para a área da saúde. Sob esse viés, é discutida no referido artigo a intensificação do processo de medicalização da infância. A discussão histórica da psiquiatria e a escola é, no artigo, desvelada, evidenciando a medicalização e a patologização da vida e das relações de poder.

"Notas sobre fracasso e diversidade: os sentidos do aprender e do não aprender na escola" retrata diferentes proposições teóricas sobre as teorias do fracasso escolar e de que forma a perspectiva da diversidade cultural pode ressignificar essa questão, afastando-se da dimensão biológica para a sócio-histórica de interpretação da realidade. O fracasso escolar é, nesse sentido, ressignificado para que possa ganhar uma nova roupagem de compreensão das diferentes abordagens educacionais e da consideração da diversidade social.

Dividido em três partes, propõe: uma análise crítica das teorias biologizantes do fracasso escolar, que concorrem para que os discursos pedagógico e médico contribuam para a produção de dispositivos normalizadores sob os quais os sujeitos são classificados como desviantes; uma análise sobre a importância dos estudos culturais para a ressignificação da compreensão sobre o fracasso escolar, na qual são considerados os efeitos do determinismo biológico constituído sob paradigmas positivistas, no deslocamento, no que se refere à escrita, dos estudos da linguagem aos estudos do campo biológico; e, por fim, o destaque à perspectiva da diversidade cultural para a compreensão do processos de construção de conhecimentos.

No artigo intitulado "Fracasso escolar e medicalização" são apresentadas as reflexões sobre a aprendizagem relacionadas aos procedimentos metodológicos que culminam em dificuldades de aprendizagem e no fracasso escolar. Metodologias inadequadas, dificuldades de lidar com a heterogeneidade social dos alunos, falta de mediação do conhecimento e baixa formação de professores são partes da realidade que apenas legitimam a medicalização da educação. A discussão empreendida revela caminhos tortuosos pelos quais ações escolares perpetuam práticas características de uma escola excludente. 
Sob diagnóstico sugestivo de TDAH, posteriormente definido como discalculia, é utilizado um estudo de caso, cuja discussão aborda o processo de normalização do sujeito que não corresponde ao padrão de normalidade socialmente vigente instituído e desconsidera o panorama da multiplicidade de aspectos implicados na produção do fracasso escolar, uma vez que seus determinantes perpassam e constituem-se nas/das relações sociais em suas diferentes esferas. O que requer o enfrentamento do fracasso escolar a partir da perspectiva de superação e não de perpetuação do mesmo.

"Discurso patologizante: o sujeito-aluno como origem e causa do fracasso escolar", evidencia as contribuições da perspectiva teórico-metodológica de análise do discurso de filiação pêcheuxtiana, para realizar uma crítica imperativa à discursividade patologizante e de seus efeitos como constitutiva de uma realidade discriminatória excludente e produtora de experiências do "não aprender na escola".

De maneira contundente são tecidas considerações a respeito de como discursos medicalizantes, representados ideologicamente como de autoridade, desqualificam a condição do aluno enquanto autor, atribuem às suas produções escritas falta de sentido e, dessa forma, legitimam e naturalizam o fracasso como decorrente de limitações individuais e intrínsecas aos alunos. Com o trabalho interpretativo alicerçado pela referida vertente teórica, são apresentados e discutidos processos de significação que explicitam os sentidos de patologização no discurso pedagógico ao (re) produzirem a máxima de que o fracasso escolar é de responsabilidade do aluno, escamoteando os vários determinantes políticos, econômicos, culturais que atravessam os processos de ensino-aprendizagem. Ainda, ganham relevância, nessa discussão, como discursos medicalizantes são institucionalizados e marcam o corpo da criança, como aquela que não aprende, ao mesmo tempo em que silenciam críticas ao sistema educacional, assim como as diferentes formas de estar na língua e de se relacionar com o conteúdo escolar.

“O discurso sobre dislexia no DSM-5 e suas implicações no processo de medicalização da educação" caracteriza o artigo que trata da análise do discurso apresentado no DSM, Manual Diagnóstico e Estatístico de Transtornos Mentais, utilizado pelos profissionais da saúde. Nesse texto se discute sobre a construção biologizante do documento especificamente com relação à Dislexia, tendo desdobramentos significativos para a análise da trajetória escolar dos estudantes e a construção de laudos técnicos. A adoção dos critérios propostos de forma descontextualizada e a-histórica promove um encarceramento do sujeito, com perdas da subjetividade e da compreensão de suas relações sociais. 
A discussão empreendida destaca, dentre outros aspectos, a constituição de diagnósticos desatrelados do contexto sociocultural em que estudantes ou adultos em condição não escolar manifestam ou produzem sintomas na leitura, frequentemente vinculados a desordens neurobiológicas e quantificados por meio de medidas padronizadas que, ao legitimam sob o status de doença modos de ser e estar no mundo que não correspondem ao padrão de normalidade imposto, marcam a incapacidade de aprender como um dos pilares que sustentam o processo de medicalização da aprendizagem.

No artigo "E quando a criança não corresponde às expectativas da escola? Reflexões sobre a relação com a família na busca por um diagnóstico" é relatada pesquisa de natureza bibliográfica e de campo, que objetivou a compreensão acerca do modo pelo qual a escola tem respondido a crianças diagnosticadas com Transtorno de Déficit de Atenção e Hiperatividade (TDAH) do ponto de vista do trabalho pedagógico e da relação com a família. Para tal, é apresentado um estudo de caso, a partir do qual são destacados aspectos reveladores da compreensão da condição de aluno que, para além do que é exigido pela escola, em termos cognitivos e de aprendizagem, acaba por ser apoiada no que é definido no texto como o "modo de ser na escola", constituído a partir de expectativas do adulto, distanciando a escola de sua função precípua de acolher a diversidade e a diferença, em detrimento da desresponsabilização do trabalho pedagógico.

São apresentadas reflexões voltadas à avaliação diagnóstica a que são submetidas as crianças que não correspondem a esse modo idealizado de ser na/da escola, aos encaminhamentos equivocados, à necessidade de abordagem multidisciplinar, à ausência ou falta de diálogo entre escola e família, com vista a enfatizar o processo de responsabilização hierarquizante sofrido pela criança submetida a processos de medicalização deflagrados pelo despreparo da escola e precarização do trabalho docente, que desconsidera a formação integral e o bem estar da criança.

A partir de um estudo de caso são relatadas tentativas, por parte de uma família de uma criança diagnosticada com TDAH, na busca, junto à escola, por soluções pedagógicas para as demandas dessa criança, ao mesmo tempo em que são reveladas as fragilidades dessa escola na condução de tais soluções, ao transferir para essa família, bem como para outros profissionais, a responsabilidade pela resolução das mesmas, em contextos clínicos, à medida em que condiciona tais demandas e soluções a encaminhamentos e tratamentos para outros profissionais, sem questionar o modo como vem lidando com a diversidade e a diferença. Ao abdicar do trabalho com a diversidade e a diferença, supervalorizando a obediência e subserviência ao regulamento, a escola ignora sistematicamente seu papel fundamental de 
preparação do sujeito para o exercício autônomo e pleno da cidadania.

O artigo "Políticas de avaliação externa e a medicalização da educação: dos sentidos do "não aprender" até o "não ensinar" objetivou a análise de políticas de avaliação externa e seus efeitos quanto ao "não aprender" e ao "não ensinar", como marcas da culpabilização e medicalização da educação. Por meio de um estudo bibliográfico e de campo é abordada e discutida a lógica classificatória das avaliações no âmbito das políticas e seus efeitos tanto na organização do trabalho pedagógico, quanto na constituição dos modos de ser aluno e de ser professor submetidos ao enquadramento a resultados e padrões derivados de interesses mercadológicos. Sob esses efeitos, sujeitos que não correspondem às expectativas quantitativas e classificatórias são culpabilizados por não atenderem padrões de normalidade idealizados.

No texto é ressaltada a responsabilização unilateral sobre a avaliação, uma vez que tal responsabilização, invariavelmente, recai sobre o professor e a escola, evidenciando como fracasso de ambos os baixos índices alcançados frente às metas idealizadas previstas no ranqueamento de escolas publicizado pelo Estado. Determinantes sociais, políticos e econômicos, dentre outros, acabam por ser desconsiderados nesse processo, contribuindo para que os resultados das avaliações externas classificatórias adotadas pelo Estado reproduzam a lógica da exclusão.

$\mathrm{O}$ artigo "Medicalização da educação e os sentidos do não aprender discursivizados na documentação pedagógica: um olhar para o discurso da escola" objetivou compreender os sentidos sobre o não aprender discursivizados por uma escola de Ensino Fundamental apontada, na região em que se localiza, como a que possui o maior número de professores com queixas sobre alunos que não aprendem. A partir de pesquisa documental, são discutidas, especificamente em relação à documentação pedagógica de duas crianças em início de apropriação da escrita, a naturalização, decorrente dessa discursivização, da constituição de sentidos sobre o não aprender, a partir das tendências medicalizadora e patologizadora dos processos educativos, que promovem, no interior da escola, a proliferação de doentes e doenças do não aprender; bem como a compreensão equivocada sobre a documentação pedagógica, entendida como mero registro de informações sobre o alunado, em vez de ser valorizada como lugar de constituição e circulação da memória educativa, portanto de natureza dialógica, ao contemplar a multiplicidade de vozes que são discursivizadas e que discursivizam sobre a criança.

$\mathrm{Na}$ discussão empreendida assume relevo o assujeitamento dessas crianças no processo de apropriação da linguagem escrita, bem como a naturalização de sentidos do não 
aprender constituídos sob tendências medicalizadora e patologizadora dos processos educativos. Em contraponto, é destacada a compreensão de linguagem escrita como atividade cultural complexa; de documentação pedagógica como lócus, para a escola, para reflexão e análise dos processos educativos, oportunizando narrações diversas em que os roteiros são escritos a partir das vozes nas relações de cada um, em detrimento de seu reducionismo a prontuários e/ou laudos, cujo uso no ambiente escolar pode ser tomado como um exemplo da subjetivação do discurso médico pela educação, nos quais figuram, além de informações médicas e cópias de exames, registros vagos sobre trajetórias educacionais, muitas vezes apoiados no senso comum, cujas narrativas abordam, invariavelmente, apenas dificuldades apresentadas pelas crianças.

No artigo "A escola $\mathrm{e}$ o ensino fundamental $I$, frente às dificuldades de aprendizagem: aspectos para uma pauta de discussões sobre (des) medicalização da educação e o êxito do(a)s escolares" são explorados aspectos sobre o papel da escola e o ensino de escolares, diante das dificuldades de aprendizagem apresentadas durante o Ensino Fundamental I, que dizem respeito ao necessário distanciamento de diagnósticos que têm levado à medicalização da Educação. A discussão sobre tais aspectos é apoiada em teorizações que ressaltam a importância do ensino intencional, da ação-reflexão-ação docente, com destaque para intervenções pedagógicas, em lugares diversos do espaço escolar, que visam atender necessidades de aprendizagem apresentadas pelas crianças, sobretudo, aquelas com dificuldades na realização das atividades. Como proposta metodológica, ganha relevância a "aula passeio", sob a perspectiva de que possibilita ensejar possibilidades outras para que as crianças reconheçam e sistematizassem, com ajuda de parceiro mais experiente, as práticas de leitura e escrita propostas.

São tecidas críticas sobre os efeitos do processo de medicalização da educação que distanciam a atividade docente da essencialidade didático-pedagógica. Sob essa compreensão, os professores são alertados de que não se trata de apenas considerar de forma generalizante a eficácia dos métodos e sua classificação como bons ou ruins, ao serem convocados - na contramão das prescrições homogeneizantes das práticas escolares advindas desde a formação inicial de professore(a)s, mediante as políticas públicas centradas em índices que não dizem respeito às especificidades do desenvolvimento humano - a repensarem tais prescrições em favor das ofertas a cada criança, compreendida em suas singularidades.

O artigo "Promoção do letramento versus medicalização do Ensino Superior: contribuições de uma abordagem fonoaudiológica de orientação sócio-histórica", evidencia como, de forma mais sensível, a partir da última década, contradições e problemas 
vêm sendo deflagrados em função da expansão do ingresso de pessoas no Ensino Superior brasileiro. A heterogeneidade dos acadêmicos quanto às diversas e desiguais condições de letramento resulta em diferentes possibilidades de participação na formação acadêmicoprofissional.

Somado ao que vem ocorrendo, tradicionalmente, em outros níveis de formação, também no ensino superior um número significativo de alunos que não atendem às expectativas e demandas de leitura e escrita de textos pertinentes a esse contexto acadêmico vem sendo considerado, a partir de uma lógica medicalizante, como problemas/distúrbios/disfunções associadas a limitações de natureza orgânica-perceptuais, cognitivas e/ou comportamentais. A gravidade e a força dessa lógica que atravessa o contexto educacional em todos os seus níveis e modalidades de ensino é denunciada, pois tiram de cena/negam os determinantes econômicos, culturais, políticos que produzem condições restritas de letramento e, portanto, de acessibilidade à educação, entendida como garantia do ingresso, da permanência e de uma formação de qualidade que favorece a emancipação e exercício da cidadania.

Apesar da evidência de que a experiência escolar anteriormente vivida não garantiu a parcela significativa dos alunos condições de leitura e escrita suficientes para participar ativa e criticamente de um curso de graduação, uma das respostas diante de tal realidade tem sido o encaminhamento de alunos para atendimentos clínicos fonoaudiológicos para superarem supostas dificuldades/distúrbios de leitura e escrita. Para o enfrentamento dessa problemática são apresentadas, a partir da discussão de um caso clínico, contribuições de uma abordagem fonoaudiológica, assentada numa perspectiva sócio-histórica, junto a um acadêmico diagnosticado como disléxico, matriculado no ensino superior. Conduzida a partir de práticas de leitura e escrita envolvendo diferentes gêneros discursivos e a análise de seus contextos de produção e de circulação, como histórica e socialmente determinados, o processo clínico objetivou a ressignificação, por parte do referido participante, de uma condição de leitor e escritor marcada pelo estatuto de incapacidade, de resistência e de sofrimento, para um lugar de autoria e, portanto, para o estabelecimento de relações com a linguagem escrita carregada de sentidos.

\section{$\mathrm{O}$ artigo "A relação de alunos de fonoaudiologia com a leitura e escrita a partir de} uma oficina de letramento" discute, com base numa Oficina de Letramento Acadêmico, as diferentes relações de sofrimento que os estudantes universitários possuem diante da escrita. O texto traz as diferentes posições assumidas pelos estudantes antes e depois da Oficina, o que permitiu uma ressignificação de uma trajetória educacional de fracasso e dificuldades 
escolares para uma nova relação com a linguagem escrita. $O$ texto evidencia que a exclusão educacional se perpetua na universidade que, diante das exigências acadêmicas, apenas legitima o processo de patologização anteriormente instalado.

A partir de dois eixos de análise, são destacadas: as dificuldades de leitura e escrita apresentadas pelos estudantes da universidade que, dentre outros aspectos, evidenciam a supervalorização, por parte dos universitários, dos aspectos normativos da língua, frente à preocupação com a adequação às normas linguísticas e formais que caracterizam a diversidade de gêneros, em especial os gêneros acadêmicos, cuja práticas de leitura e escrita adotadas no contexto universitário promovem, em grande medida, o distanciamento da linguagem como prática discursiva; bem como os efeitos da oficina de letramento na posição subjetiva dos mesmos, dentre os quais assumem relevância a superação de situações cotidianas limitantes, a maior participação da/na comunidade acadêmica e maior desculpabilização do estudante frente às queixas apresentadas, o que possibilitou também maior autonomia e diminuição de angústias e sofrimentos deflagrados pela condição de culpabilização e imobilização frente ao protagonismo necessário na constituição do sujeito pelas/nas práticas discursivas de escrita.

No artigo "Sempre fui meio termo": a clínica fonoaudiológica e a construção de narrativas no contexto da Educação Superior", a narrativa na clínica fonoaudiológica evidencia uma trajetória de sofrimento com a linguagem escrita, por parte do estudante universitário, que refrata os diferentes modos como ele constrói uma história de vida que dê sentido ao seu sofrimento. A busca pelo diagnóstico na clínica fonoaudiológica é uma legitimação desse processo, evidenciado a partir de um estudo de caso de um universitário. Tal processo, desvelado com base em subsídios das áreas da Linguística, da Sociologia e da Fonoaudiologia e por meio da entrevista clínica e de material por ele produzido, resgata sentidos e a história de vida desse universitário em sua relação com a linguagem escrita.

Concomitantemente, a ressignificação da clínica como local de acolhimento, a partir do diagnóstico para as dificuldades educacionais, ressalta o despreparo da universidade no enfrentamento de questões dessa natureza, ao mesmo tempo em que possibilita à fonoaudiologia, a partir de uma perspectiva enunciativo-discursiva, constituir-se em lócus para favorecer a compreensão sobre os aspectos sociais implicados na construção de todo o percurso do estudante.

No artigo "Fonoaudiologia na escola: a abordagem dialógica como estratégia desmedicalizante" são tecidas críticas às abordagens medicalizantes, considerando a apresentação e discussão de uma proposta fonoaudiológica comprometida com a 
sistematização e com o implemento de práticas que permitem um olhar sobre a criança, o conhecimento e as práticas pedagógicas capaz de potencializar o lugar do aprendiz, do professor e do processo de ensino-aprendizagem como próprios das relações estabelecidas na esfera da Educação para atender o seu papel, constitucionalmente reconhecido: a democratização dos bens simbólicos construídos social e historicamente.

Desenvolvida no período de dois anos, numa escola pública da cidade de São Paulo, e fundamentada a partir da perspectiva teórico-metodológica dialógica, de cunho bakhtiniano, essa proposta foi orientada a partir da escuta de vozes, como destacado no texto, nem sempre "consonantes", que atravessam e constituem o contexto escolar. Realizada em três etapas e envolvendo professores, estudantes dos anos iniciais e professores de seis salas de apoio, foram criados espaços para colocar em diálogo visões acerca do processo de aprendizagem dos estudantes, bem como de possíveis dificuldades que podem fazer parte do mesmo. Dessa perspectiva, a desestabilização de verdades estigmatizantes, assumida com um dos objetivos da proposta, foi ocorrendo a partir dos diálogos produzidos em torno e em relação às crianças ditas "problemas", na medida em que os professores foram convocados a olharem para tais crianças não como aquelas desviantes de um grupo homogêneo, mas como parte de um grupo de crianças reais, com potencialidades e com experiências diversas e particulares.

Cabe destacar, ainda, que a proposta analisada nesse artigo, coerentemente à abordagem dialógica assumida, situa de forma clara a posição do fonoaudiólogo que se insere no contexto educacional como profissional comprometido com o fazer pedagógico. Nesse sentido, o artigo contraria a perspectiva adotada tradicionalmente, por grupos de fonoaudiólogos inseridos no contexto escolar, que valoriza a identificação e classificação de supostos distúrbios de aprendizagem, com objetivo de preveni-los e/ou superá-los, a partir de ações de estimulação dirigidas aos alunos ou de orientações e instrumentalização aos professores. Nessa análise, o papel da Fonoaudiologia é ressignficado no contexto escolar, a partir da potencialização do saber do professor e do estabelecimento de parcerias/diálogos que promovam o compartilhar de conhecimentos acerca da linguagem, sobretudo, dos diferentes aspectos envolvidos com processos de letramento e usos sociais da escrita.

No artigo "Os efeitos de práticas e discursos no processo educacional de um sujeito com suposta dificuldade de leitura e escrita", a partir de um estudo de caso de uma criança com queixa de dificuldade de escrita é apresentada a análise de como discursos e práticas medicalizantes são instituídos, desconsiderando aspectos envolvidos com as práticas educacionais e com as diferentes formas de aprendizagem de cada sujeito, antes mesmo da confirmação de um diagnóstico clínico. O artigo evidencia como já a partir de um "pré- 
diagnóstico" estabelecido, em geral no contexto educacional, tais abordagens produzem efeitos negativos que constituem a subjetividade da criança, bem como perpassam o contexto educacional, produzindo experiências que resultam no "não aprender'.

Uma análise crítica a respeito dos mecanismos e das razões que levam à construção de pré-diagnósticos atribuídos às crianças, em geral por educadores, evidenciam o fato de que, após a confirmação dos mesmos por profissionais da saúde, com base na descrição de comportamentos das crianças no contexto escolar, não ocorrem mudanças que promovam a superação das supostas dificuldades e o avanço do aprendizado escolar. Dessa perspectiva, diagnósticos, acima de tudo, servem para selar limitações/distúrbios/deficiências como decorrentes de problemas dos alunos suficientes para justificarem o fracasso escolar. Sendo assim, as discussões encaminhadas no referido artigo deflagram o paradoxo existente no fato de que o diagnóstico de supostos distúrbios, a descrição de sintomas, de causas e de classificações atestados nos laudos e relatórios, ao invés de concorrer para o entendimento da criança, de suas particularidades e de seus modos de aprender servem, muito mais, para subsidiar práticas pedagógicas excludentes. Como modo de enfrentamento de tal paradoxo, é também destacada a importância do implemento de parcerias entre profissionais da área da Saúde e da Educação.

No artigo "Medicalização e a atuação fonoaudiológica frente à queixa escolar", são colocados em cena relatos produzidos por fonoaudiólogos acerca de sua atuação clínica junto a crianças com queixas escolares para apreender como, em seus discursos, estão materializadas posições ideológicas em torno das tensões estabelecidas a partir de diferentes olhares em torno da "queixa escolar", do "fracasso escolar" e da "medicalização".

Apesar de a queixa escolar estar correlacionada ao fracasso escolar e de ambos os fenômenos, construídos por significações negativas, desqualificatórias e de sofrimento, atravessarem os muros da escola, produzindo efeitos nas crianças, nos educadores e nos familiares, é destacado o fato de serem, ainda, restritos os estudos que os analisam como tais, engendrados a partir de princípios e de mecanismos medicalizantes produzidos, complementarmente, por profissionais das áreas da saúde e da educação. Indo na contramão de estudos e de práticas que, tradicionalmente, reiteram e naturalizam uma lógica organicistabiologizante, a partir perspectiva teórico-metodológica sócio-histórica, os fonoaudiólogos são convocados a uma escuta crítica-responsiva de discursos que, contraditoriamente, evidenciam ações intersetoriais, envolvendo fonoaudiólogo e educadores corroborando ou contrapondo abordagens e práticas medicalizantes que vêm sendo (re) produzidas no contexto escolar. 
Assumem relevância, na discussão proposta, tensões existentes entre perspectivas ideológicas que, diversamente, orientam a atuação, o papel social da Fonoaudiologia e as relações estabelecidas com o campo da Educação: - uma denominada como biomédica que, assentada em práticas focadas na descrição de sintomas e causas e na classificação de supostos distúrbios e/ou dificuldades fornece justificativas para o fracasso escolar como inerentes aos alunos e/ou aos seus familiares; - outra comprometida com uma concepção de sujeito, de seus processos de desenvolvimento e de escolaridade assentada na escuta e no acolhimento das crianças, de seus familiares e das queixas escolares, como sociais e historicamente constituídos.

No decorrer da leitura dos artigos que integram este Dossiê, aspectos como a subjetivação do discurso médico pela educação e áreas afins, que condiciona os processos de constituição do sujeito e da/na linguagem escrita ao reducionismo padronizado e idealizado de distintos modos de ser e de se comportar; a hierarquização de saberes profissionais; a constituição de processos medicalizantes e patologizantes como processos normatizadores desses distintos modos de ser e de se comportar; a excessiva valorização de práticas mecanicistas e preventivistas que originam ou decorrem dessa normatização, dentre outros, são recorrentemente abordados e discutidos, tendo como base a crítica ao controle técnico sobre a vida.

Sob a expectativa de que contribuam para a necessária reflexão sobre a temática proposta e o debate que se faz urgente acerca dos sentidos sobre o não aprender gerados no contexto de concepções e práticas medicalizantes, desejamos a todos uma boa leitura.

\section{Como referenciar este artigo}

GIROTO, C. R. M.; BERBERIAN, A. P.; SANTANA, A. P. O. Medicalização da educação e os sentidos do não aprender. Revista Ibero-Americana de Estudos em Educação, Araraquara, v. 15, n. esp. 5, p. 2789-2802, dez. 2020. e-ISSN: 1982-5587. DOI: https://doi.org/10.21723/riaee.v15iesp5.14558

Submetido em: 10/01/2020

Revisões requeridas em: $25 / 05 / 2020$

Aprovado em: 30/10/2020

Publicado em: 01/12/2020 